\title{
Effect of tensile load on high temperature oxidation of CoNiCrAIY coating
}

DOI:

10.1016/j.surfcoat.2018.08.015

\section{Document Version}

Accepted author manuscript

Link to publication record in Manchester Research Explorer

\section{Citation for published version (APA):}

Chen, Y., Fan, X., Sun, Y., \& Zhang, W. (2018). Effect of tensile load on high temperature oxidation of CoNiCrAlY coating. Surface and Coatings Technology, 352, 399-405. https://doi.org/10.1016/j.surfcoat.2018.08.015

\section{Published in:}

Surface and Coatings Technology

\section{Citing this paper}

Please note that where the full-text provided on Manchester Research Explorer is the Author Accepted Manuscript or Proof version this may differ from the final Published version. If citing, it is advised that you check and use the publisher's definitive version.

\section{General rights}

Copyright and moral rights for the publications made accessible in the Research Explorer are retained by the authors and/or other copyright owners and it is a condition of accessing publications that users recognise and abide by the legal requirements associated with these rights.

\section{Takedown policy}

If you believe that this document breaches copyright please refer to the University of Manchester's Takedown Procedures [http://man.ac.uk/04Y6Bo] or contact uml.scholarlycommunications@manchester.ac.uk providing relevant details, so we can investigate your claim.

\section{OPEN ACCESS}




\section{Accepted Manuscript}

Effect of tensile load on high temperature oxidation of CoNiCrAlY coating

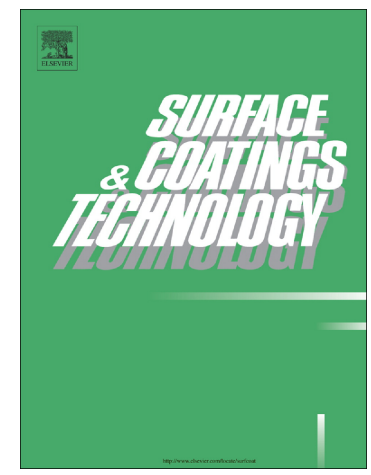

Yao Chen, Xueling Fan, Yongle Sun, Weixu Zhang

PII: S0257-8972(18)30820-X

DOI: doi:10.1016/j.surfcoat.2018.08.015

Reference: SCT 23673

To appear in: Surface \& Coatings Technology

Received date: 29 April 2018

Revised date: 2 August 2018

Accepted date:

4 August 2018

Please cite this article as: Yao Chen, Xueling Fan, Yongle Sun, Weixu Zhang, Effect of tensile load on high temperature oxidation of CoNiCrAlY coating. Sct (2018), doi:10.1016/j.surfcoat.2018.08.015

This is a PDF file of an unedited manuscript that has been accepted for publication. As a service to our customers we are providing this early version of the manuscript. The manuscript will undergo copyediting, typesetting, and review of the resulting proof before it is published in its final form. Please note that during the production process errors may be discovered which could affect the content, and all legal disclaimers that apply to the journal pertain. 


\title{
Effect of Tensile Load on High Temperature Oxidation of CoNiCrAlY Coating
}

\author{
Yao Chen ${ }^{\mathrm{a}}$, Xueling Fan ${ }^{\mathrm{a}, *}$, Yongle Sun ${ }^{\mathrm{b}, *}$, Weixu Zhang ${ }^{\mathrm{a}}$ \\ ${ }^{a}$ State Key Laboratory for Strength and Vibration of Mechanical Structures, School of Aerospace \\ Engineering, Xi'an Jiaotong University, Xi'an 710049, China \\ ${ }^{b} S c h o o l ~ o f ~ M e c h a n i c a l$, Aerospace and Civil Engineering, The University of Manchester, Sackville \\ Street, Manchester M13 9PL, UK
}

\begin{abstract}
Oxide growth plays a critical role in the failure mechanisms of thermal barrier coating (TBC) systems. This study is aimed to investigate the chemomechanical coupling oxidation behavior of CoNiCrAlY coating which is widely used as bond coat in TBC systems. Oxidation experiments at $1000{ }^{\circ} \mathrm{C}$ were conducted on both load-free and tension-loaded specimens. Microscopic examination was also performed using scanning electron microscopy and Raman spectroscopy. The experimental results show that the oxidation of the CoNiCrAlY coating was accelerated by the applied tensile load. In the oxide scale of the load-free specimen, both $\alpha$-alumina and $\theta$-alumina were present when the oxidation duration was short ( $\leq 15$ hours), but the $\theta$-alumina transformed to $\alpha$-alumina after 20 -hour oxidation. By contrast, in the tension-loaded specimen, mixed $\alpha$-alumina and $\theta$-alumina were found even after oxidation for 20-60 hours. This phenomenon suggests that the tensile load can cause delay in the phase transformation from fast-growing $\theta$-alumina to slow-growing $\alpha$ alumina. A new mechanism based on the theoretically derived effect of mechanical work on the free energy for alumina phase transformation has been proposed to explain the experimental observations.
\end{abstract}

Keywords: Oxide growth, alumina, chemo-mechanical coupling, phase

*Correspondence, Email: fanxueling@ mail.xjtu.edu.cn (X.L. Fan)

yongle.sun@manchester.ac.uk; sunyongletl@gmail.com (Y.L. Sun) 
transformation, thermal barrier coatings

\section{Introduction}

Thermal barrier coating (TBC) systems are the main constituent parts of hot end components of turbine blades in modern gas turbines, and they comprise three layers at least, i.e. ceramic top coat (TC), metallic bond coat (BC) and superalloy substrate [15]. Thermally grown oxide (TGO) is an additional thin layer formed between $\mathrm{BC}$ and $\mathrm{TC}$, as a result of $\mathrm{BC}$ oxidation during the service of $\mathrm{TBC}$ systems. In the long-term operation of a gas turbine, the TGO continues growing, and consequently it alters the local interface morphology and generates significant stresses, which act as an important driving force of cracking at the interfaces and surface in TBC systems [6-8]. Therefore, it is important to understand the high temperature oxidation behavior of $\mathrm{BC}$ (i.e. the TGO growth) in TBC systems.

Previous experimental studies on oxidation in TBC systems were carried out mainly for load-free BC layer sprayed on planar test piece (mainly on wafer) and then oxidized at high temperature; the research attention was placed to the microstructure, the spraying process, the surface treatment before the oxidation and so on [9-11]. The growth behavior of the TGO between BC and TC was also studied [12-14] in a way similar to that for the specimens without TC. Different aspects of the oxidation behavior have been examined. For instance, material scientists are mainly interested in the oxidation mechanism and the growth rate of an oxide film, while mechanicians are devoted to simplifying oxidation process so as to predict the oxide growth stress and 
the associated crack initiation and propagation at the oxide/substrate interface, for the development of a series of failure theories [15-18]. It thus appears that the current understanding of the oxidation process of $\mathrm{BC}$ in $\mathrm{TBC}$ systems is decoupled between chemistry and mechanics. By contrast, in other similar areas of research, such as lithium batteries, it has been found that some chemical reaction phenomena are actually associated with the stress state, which acts as a chemical reaction condition and affects the chemical reaction rate [19-21]. Therefore, it is believed also necessary to examine the potential chemo-mechanical coupling during TGO growth in order to better understand the oxidation behavior of $\mathrm{BC}$ and its associated failure mechanisms of TBC systems.

Despite the paucity of experimental studies on the chemo-mechanical oxidation behavior of metallic coatings, the effect of stress state on oxidation of metals/alloys is a research topic of lasting significance and interest. For instance, in 1978, Evans et al. [22] reported experimental observations showing that long-term oxidation weight gain of Zircaloy-2 changed from following the classic parabolic law to cubic law, and they asserted that the significant compressive stress developed during oxidation decelerated the oxidation reaction and proposed a chemo-mechanical coupling mechanism to account for this effect. Recently, some theoretical studies on the chemo-mechanical coupling oxidation behavior of metals/alloys have been also reported [23-27], which focused on the effect of stresses developed without external mechanical load. In parallel, experiments were also conducted to examine the effect of applied load on the oxidation 
behavior of metals/alloys. For instance, Takei and Nii [28] investigated the oxidation of $\mathrm{Ni}-20 \mathrm{Cr}-4 \mathrm{Al}$ alloy under tensile load and they found that different tensile loads could cause different oxide exfoliation areas, thereby eventually leading to different weight gain. Calvarin-Amiri et al. [29] investigated the effect of tensile load on the oxidation of $\mathrm{Ni}-20 \mathrm{Cr}$ alloy and they found that the tensile load accelerated hightemperature oxidation and the oxidation products were different between the specimens with and without tensile load. Zhou et al. [30-32] investigated the oxidation of pure nickel and Fe-20Cr alloy under compressive load, and the oxidation of pure nickel under both tensile and compressive loads; they concluded that: (1) the oxidation reaction can be accelerated by both tensile and compressive loads; (2) the grain size can be reduced under mechanical loading; and (3) the grain boundary density can be increased such that it would enhance the diffusion of oxygen ions. More recently, hightemperature three-point bending experiments have been carried out to study the oxidation of $\mathrm{MoCu}$ superalloy under tensile and compressive loads [33], and the results showed that tensile stress accelerated high-temperature oxidation, whereas compressive stress had opposite effect, which were explained via theoretically deriving the effect of stress on ion diffusion.

The previous research, as reviewed above, has shown the significant difference in oxidation behavior between the load-free metals/alloys and those under tensile/compressive loads. In this study, the oxidation behavior of CoNiCrAlY coating (i.e. typical BC in TBC systems) is investigated experimentally and theoretically. 
Section 2 deals with the details about the experiment. The results and discussion are presented in Section 3 and Section 4, respectively. Concluding remarks are made in Section 5 .

\section{Materials and method}

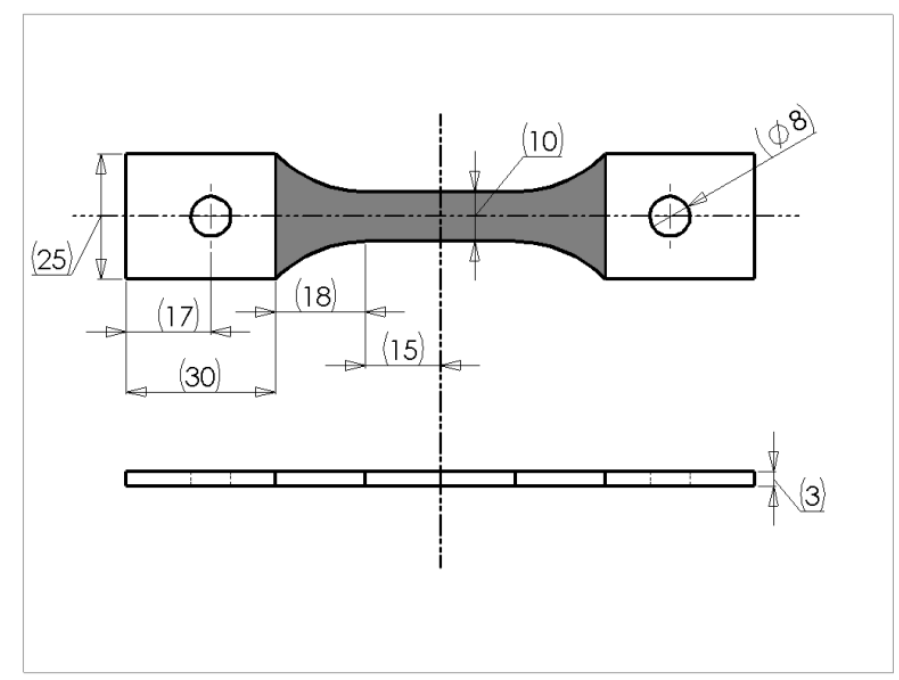

Fig. 1. Geometric configuration of the specimen (dimension in $\mathrm{mm}$ ).

Ni-based superalloy plates (K465) were used as the substrates for spraying Co32Ni-21Cr-8Al-0.5Y (wt.\%) coatings. The superalloy plates were cut into dog bone shape via wire electrical discharge machining. The Chinese standard GB/T 2039-1997 was followed, and the specimen dimension was $126 \times 25 \times 3 \mathrm{~mm}$. Fig. 1 shows the details about the geometrical configuration of the specimen. High velocity oxy-fuel (HVOF) was used to deposit a $150-\mu$ m thick CoNiCrAlY coating in the middle region of the specimen (i.e. dark part as shown in Fig. 1). It should be noted that the CoNiCrAlY coating was sprayed on both sides of the specimen and no surface treatment was 
performed. For simplicity, the ceramic TC in TBC systems was not considered in this study.

High-temperature creep machine (Jilin GuanTeng) was employed to provide uniform heating and apply tensile load to the specimen simultaneously. The test temperature was $1000{ }^{\circ} \mathrm{C}$ with a heating rate of $10{ }^{\circ} \mathrm{C} / \mathrm{min}$ and the tensile load was 900 $\mathrm{N}$ (corresponding to a nominal tensile stress of $30 \mathrm{MPa}$ ). The maximum oxidation duration was $60 \mathrm{~h}$ at the exposure temperature. Every $20 \mathrm{~h}$ the specimen was cooled in the air to the room temperature and then the weight was measured using an accurate balance with 0.1-mg sensitivity (METTLER TOLEDO ME204). After the step of weighing, the specimen was analyzed by scanning electron microscopy (SEM, FEI Quanta 200) with energy dispersive spectroscopy (EDS). The oxidation weight gain was divided by the total area of the surfaces (i.e. both sides of the specimen) on which the CoNiCrAlY coating was deposited, and then the ratio was squared, such that a parabolic oxidation kinetics law can be conveniently revealed by examining the linearity of the relationship between the squared weight gain per area and oxidation time.

\section{Results}

Fig. 2 shows the relation between the squared weight gain per area and the oxidation time of the coating specimen. The overall trend of the measurement data is similar, whether a tensile load is applied or not, and the relation does not deviate much from the parabolic law of oxide growth. However, it is evident that more oxides were formed 
when the tensile load was applied, and consequently the oxide growth rate was increased by $20 \%$.

Figs. 3 and 4 show the oxide microstructure on the surface of the coating specimen, as observed in SEM images. Comparing the results shown in Figs. 3 and 4, different oxidation products can be clearly seen for different oxidation time and load conditions. As shown in Fig. 3, for the load-free specimen, the oxidation products were regular oxide grains. Distinctive microstructures developed in the tension-loaded specimen; i.e. blade, whisker or needlelike oxidation products were observed in Fig. 4. These two types of oxides were analyzed by energy dispersive spectrometer (EDS), as shown in Figs. 5 and 6. The chemical compositions of all the oxidation products are dominated by $\mathrm{Al}$ and $\mathrm{O}$ (Figs. 5b and 6b). Therefore, the two types of oxidation products, as shown in Figs. 3 and 4, are actually different phases of alumina. It has been recognized that $\theta$ alumina usually grows with a bladelike, whisklike or needlelike morphology, while the $\alpha$-alumina grows to form a dense equiaxed microstructure [34-37]. It is thus clear that the regular oxide phase, as shown in Fig. 3, is $\alpha$-alumina, whereas the bladelike oxide phase, as shown in Fig. 4 , is $\theta$-alumina. Fig. 4 also indicates that the proportion of the bladelike oxide phase, i.e. $\theta$-alumina, reduced with the oxidation time increasing. 


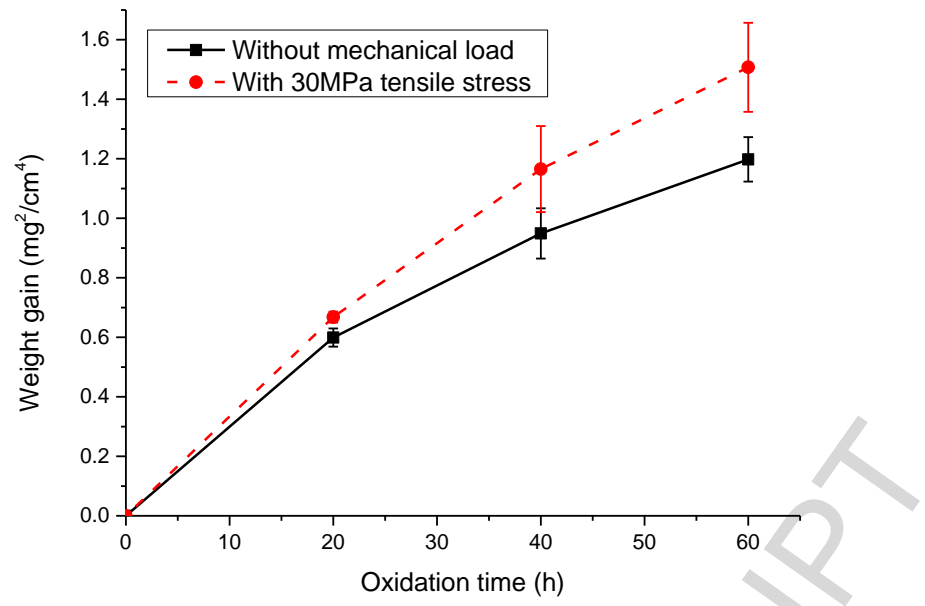

Fig. 2. Oxidation weight gain (squared ratio to area) vs. time.
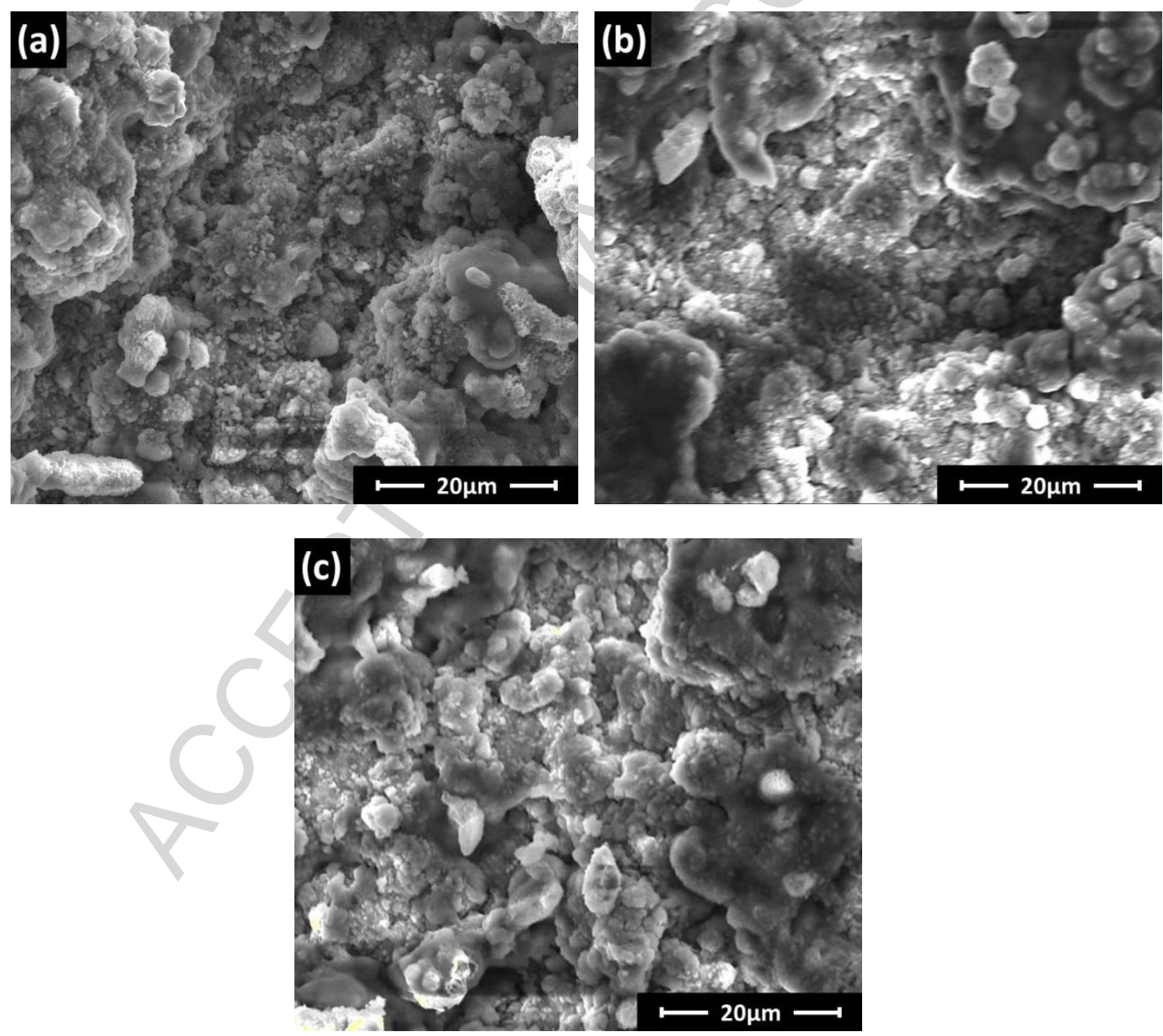

Fig. 3. Microscopic surface morphology of the coating specimen without mechanical load after oxidation for $20 \mathrm{~h} \mathrm{(a),40} \mathrm{h} \mathrm{(b)} \mathrm{and} 60 \mathrm{~h}(\mathrm{c})$. 

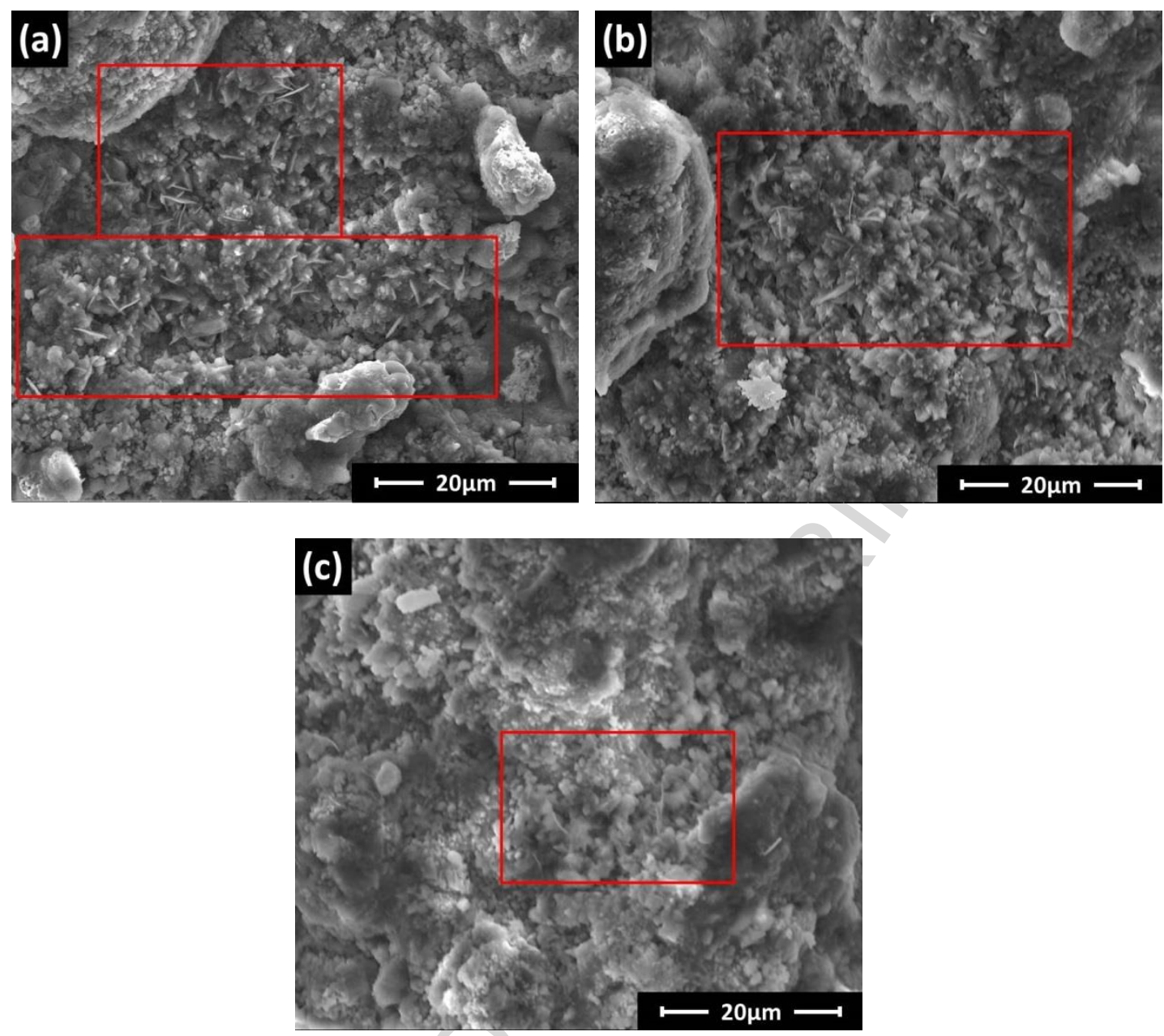

Fig. 4. Microscopic surface morphology of the coating specimen with an applied nominal tensile stress of $30 \mathrm{MPa}$ after oxidation for $20 \mathrm{~h} \mathrm{(a),} 40 \mathrm{~h}$ (b) and $60 \mathrm{~h} \mathrm{(c).} \mathrm{The}$ red rectangles indicate distinctive microstructures.

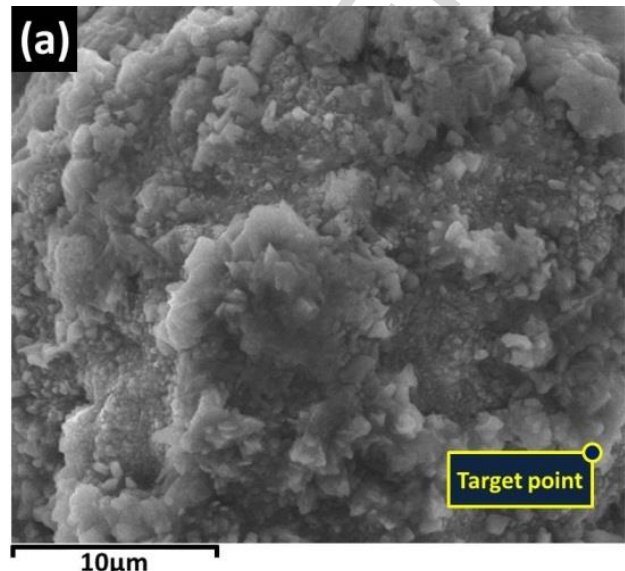

(b)

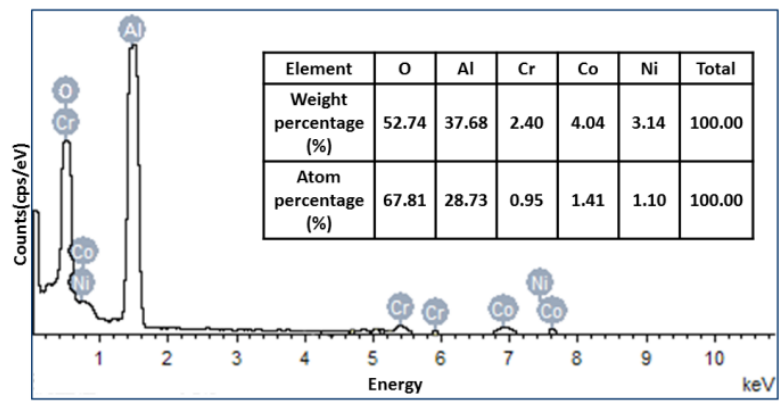

Fig. 5. (a) Microscopic surface morphology of the coating specimen without mechanical load after oxidation for $20 \mathrm{~h}$; (b) EDS spectrum for the location indicated as target point in (a). 


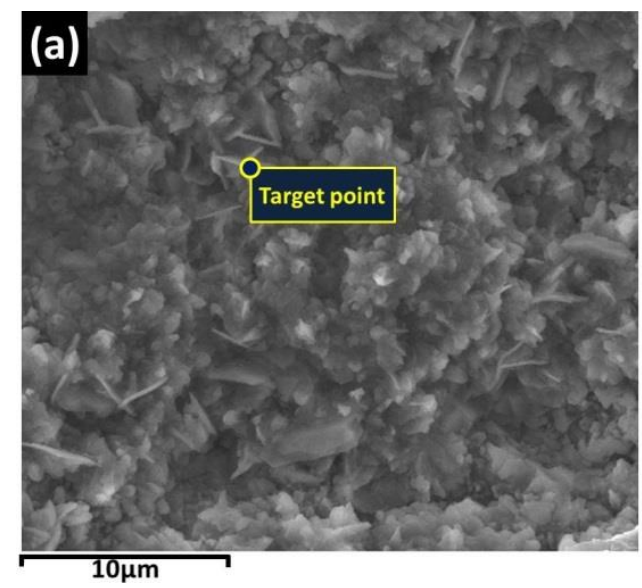

(b)

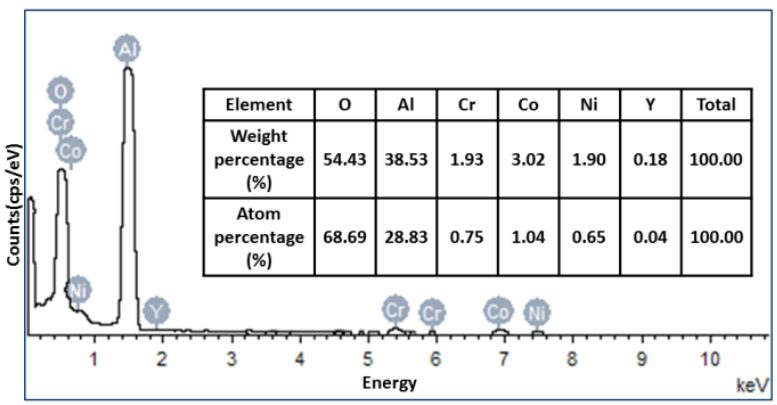

Fig. 6. (a) Microscopic surface morphology of the coating specimen with an applied nominal tensile stress of $30 \mathrm{MPa}$ after oxidation for $20 \mathrm{~h}$; (b) EDS spectrum for the location indicated as target point in (a).

\section{Discussion}

\subsection{Theoretical analysis}

It has been mentioned in Section 1 that previous experimental results showed an acceleration effect of applied tensile load on oxidation rate of some metals and alloys at high temperature $[29,32,38]$, and our experimental results for CoNiCrAlY coating, as presented in Fig. 2, are consistent with these previous observations. Such accelerated oxidation was prevalently explained as a result of the effect of stress on ion diffusion, e.g. the tensile stress enables more oxygen ions to cross the oxide layer which acts as an oxidation barrier and finally more metal ions underneath the oxide layer are oxidized. By contrast, herein we propose another mechanism to explain the tensile-stress enhanced oxidation phenomenon for the CoNiCrAlY coating.

In the CoNiCrAlY coating, alumina is the dominant oxide formed, as shown in Figs. 5 and 6 , because $\mathrm{Al}$ is the most reactive element. The $\mathrm{Al}$ oxidation generates 
metastable oxide first, e.g. $\theta$-alumina, and then it transforms to a stable oxide, i.e. $\alpha$ alumina. Eventually the oxide is only composed of $\alpha$-alumina. It has been widely recognized that the coefficient of the growth rate of $\theta$-alumina is much larger (even two orders larger in magnitude) than that of $\alpha$-alumina [37, 39-41]. From Figs. 3 and 4, it is clearly seen that the development of different phases of alumina is affected by the tensile load. Consequently, the oxidation rates are significantly different (Fig. 2) due to the effect of tensile load on alumina phase transformation. We observed both $\theta$-alumina and $\alpha$-alumina in the tension-loaded specimen, but only $\alpha$-alumina in the load-free specimen for the same oxidation time (Figs. 3-6). The $\theta$-alumina gradually disappeared with oxidation time increasing, and the transformation from $\theta$-alumina to $\alpha$-alumina was retarded when the tensile load was applied, as shown in Figs. 3 and 4 (additional short-duration oxidation experiment has been also conducted to verify this, see Section 4.2). Therefore, we propose a new mechanism that the tensile load accelerates the oxide growth via its effect on phase transformation, as schematically shown in Fig. 7. 


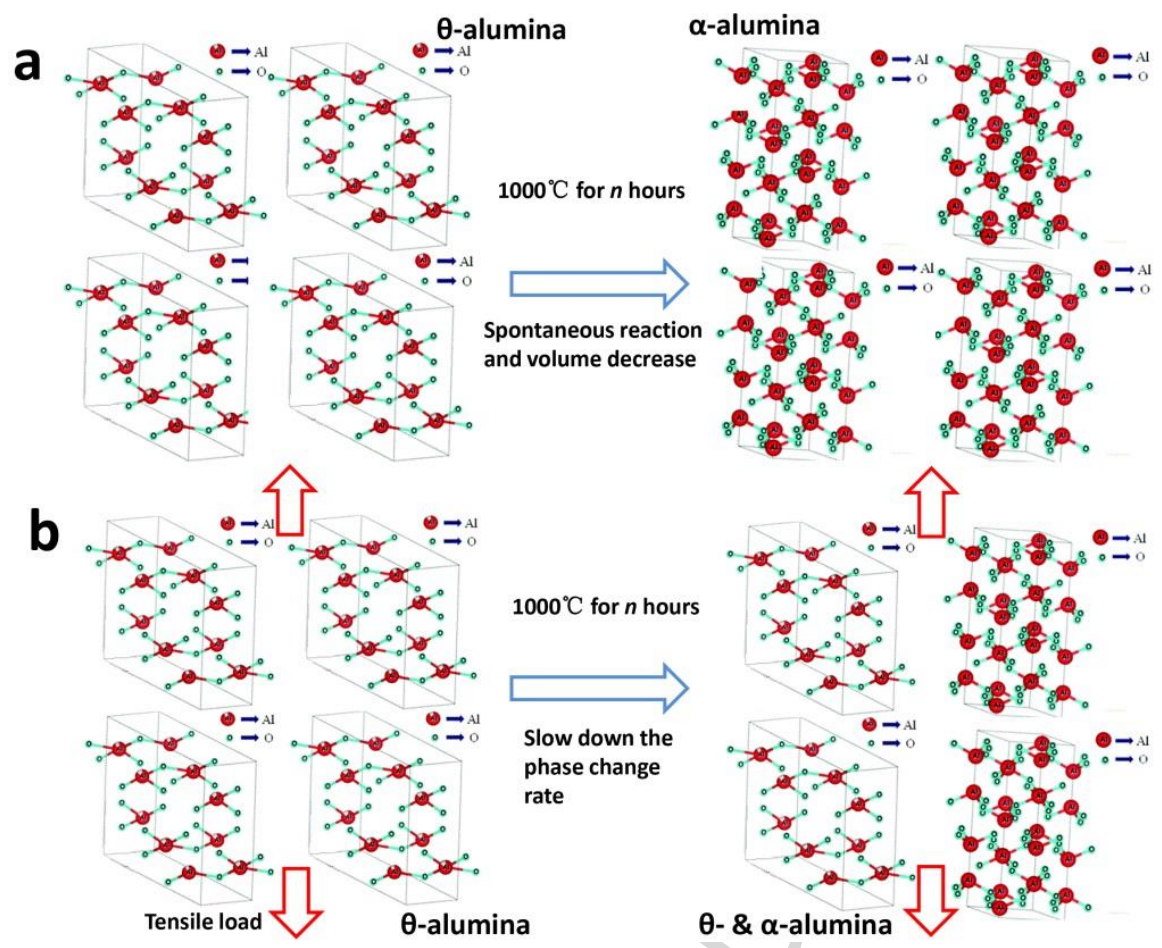

Fig. 7. Schematic diagram of $\theta$ - to $\alpha$-alumina phase transformation process [42]. The crystal structural parameters are $a=1.17 \mathrm{~nm}, b=0.57 \mathrm{~nm}, c=1.12 \mathrm{~nm}, \beta=103.34^{\circ}$ for $\theta$ alumina and $\mathrm{a}=0.47 \mathrm{~nm}, \mathrm{~b}=0.47 \mathrm{~nm}, \mathrm{c}=1.29 \mathrm{~nm}$ for $\alpha$-alumina.

Similar to the previous theoretical model of the effect of tensile load on martensitic transformation [43, 44], we present the following theoretical analysis of the effect of tensile load on alumina phase transformation during the oxidation of CoNiCrAlY coating. As a general model, both volumetric and distortional deformation is considered. Provided that the parent phase is subjected to uniaxial stress when the phase transformation occurs, the free energy change under uniaxial stress is

$$
\Delta G_{\sigma}=\tau \Delta \gamma_{0}+\sigma \Delta \varepsilon_{0}
$$

where $\tau$ and $\sigma$ are the shear and normal components of the uniaxial stress, respectively, as decomposed on the habitat surface for the phase transformation; $\Delta \gamma_{0}$ 
and $\Delta \varepsilon_{0}$ are the change of the shear strain along the habitat surface and the change of dilation strain after phase transformation, respectively.

Decomposition is performed using the Mohr Cirle, i.e.

$$
\begin{gathered}
\tau=0.5 \sigma_{1} \sin 2 \theta \\
\sigma= \pm 0.5 \sigma_{1}(1+\cos 2 \theta)
\end{gathered}
$$

Incorporating above equations into Eq. (1) we obtain

$$
\Delta G_{\sigma}=0.5 \sigma_{1} \Delta \gamma_{0} \sin 2 \theta \pm 0.5 \sigma_{1}(1+\cos 2 \theta) \Delta \varepsilon_{0}
$$

The \pm appears since the parent phase can be subjected to either tensile or compressive stress (tension is positive), and $\sigma_{1}$ stands for the absolute value of the uniaxial stress.

Along a particular angle, the $d \Delta G_{\sigma}$ reaches maximum, i.e.

$$
\frac{d \Delta G_{\sigma}}{d \theta}=\sigma_{1} \Delta \gamma_{0} \cos 2 \theta \pm \sigma_{1}(-\sin 2 \theta) \Delta \varepsilon_{0}=0
$$

when $\tan 2 \theta= \pm \Delta \gamma_{0} / \Delta \varepsilon_{0}$. If the specimen is subjected to hydrostatic pressure:

$$
\Delta G_{\sigma}=-\sigma_{1} \Delta \varepsilon_{0}
$$

In this study, the specimen was only subjected to uniaxial tensile stress, so we have $\Delta G_{\sigma}=0.5 \sigma_{1} \Delta \gamma_{0} \sin 2 \theta+0.5 \sigma_{1}(1+\cos 2 \theta) \Delta \varepsilon_{0}$ and $\tan 2 \theta=\Delta \gamma_{0} / \Delta \varepsilon_{0}$. Since the $\theta$ - to $\alpha$-alumina transformation is a volume reduction process $[45,46]$, we have $\Delta \varepsilon_{0}<0$. If $\Delta \gamma_{0}<0$, then $\tan 2 \theta>0$, i.e. $\sin 2 \theta>0$ and $\cos 2 \theta>0$, thus $\sigma_{1} \Delta \gamma_{0} \sin 2 \theta<0$ 
and $\sigma_{1}(1+\cos 2 \theta) \Delta \varepsilon_{0}<0$. Eventually we have $\Delta G_{\sigma}<0$. In contrast, if $\Delta \gamma_{0}>0$, then $\tan 2 \theta<0$, i.e. $\sin 2 \theta<0$ and $\cos 2 \theta>0$, thus $\sigma_{1} \Delta \gamma_{0} \sin 2 \theta<0$ and $\sigma_{1}(1+\cos 2 \theta) \Delta \varepsilon_{0}<0$, and eventually we still have $\Delta G_{\sigma}<0$. If the phase transformation does not introduce additional shear strain and only involves the change of dilation strain, we can always decompose the volumetric strain into vertical and parallel to the direction of the uniaxial tension. So $\Delta \varepsilon_{0}$ is the change of volumetric strain along the direction of tensile stress, while the volumetric strain perpendicular to the direction of the uniaxial tensile load does not contribute to the change in free energy, and again, we have $\Delta G_{\sigma}=\sigma_{1} \Delta \varepsilon_{0}<0$. Therefore, $\Delta G_{\sigma}$ is always less than zero if tensile stress is present, no matter how much $\Delta \gamma_{0}$ is.

The total free energy change associated with the phase transformation consists of two parts, viz.

$$
\Delta G=\Delta G_{c h e}-\Delta G_{\sigma}
$$

where $\Delta G_{c h e}$ is the free energy change with chemical origin. As this phase transformation is spontaneous, the $\Delta G_{c h e}$ is less than zero. Learning from the analysis presented earlier, we obtain $\Delta G_{\sigma}<0$, so at last, we have $0>\Delta G>\Delta G_{c h e}$. In other words, the tensile stress slows down the phase transformation from $\theta$-alumina to $\alpha$-alumina, because the less decrease in the free energy causes slower phase transformation.

If the specimen was subjected to compressive stress, same analysis method could be applied and in such a case we find that $\Delta G_{\sigma}>0$. Then we obtain $0>\Delta G_{c h e}>\Delta G$, so 
the compressive stress accelerates the phase transformation from $\theta$-alumina to $\alpha$ alumina.

\subsection{Short-duration oxidation}

In the main experiments presented in Section 3, no microscopic morphology typical for $\theta$-alumina was observed in the load-free specimen that was exposed to high temperature for $20-60 \mathrm{~h}$. This result may suggest that the $\theta$-alumina has already transferred to $\alpha$-alumina before the microstructural examination was performed. To verify this, we conducted an additional short-duration oxidation experiment as follows.

The same K465 superalloy was used to prepare coating specimen. But for the additional experiment, the specimen was a disk with edge chamfering $(2.54 \mathrm{~cm}$ in diameter and $3 \mathrm{~mm}$ in thickness). The same proportion of CoNiCrAlY powder was used to spray a $150-\mu \mathrm{m}$ thick coating on the disk using the same parameters for the HVOF process, without any surface treatment. The specimen experienced oxidation in the furnace (MTI KSL-1700X) at same high temperature of $1000{ }^{\circ} \mathrm{C}$. The microscopic morphology of the oxidation product was observed by SEM (FEI Quanta 200) when the oxidation lasted for 5 h, 10 h, 15 h and 20 h. Then we used the Raman spectroscopy (HORIBA JOBIN YVON) to analyze the chemical composition of the oxide for the oxidation time of $5 \mathrm{~h}$ and $20 \mathrm{~h}$. The wavelength of the excitation of the Raman spectroscopy was $476 \mathrm{~nm}$ and the power of the laser was $10 \mathrm{~mW}$. It should be mentioned that Raman spectroscopy is a suitable method to analyze the components of the thin 
oxide layer because of the non-destructiveness and the small depth of laser (about dozens of nanometers). As the metal does not have any Raman peak, the collected signals all come from the oxide.

Fig. 8 shows the microstructures of the oxidation products without any mechanical load. It is clearly seen that $\theta$-alumina was formed in the 5 -h oxidation product but absent in the 20-h oxidation product. The $\theta$-alumina was also observed in the SEM images of specimens oxidized for $10 \mathrm{~h}$ and $15 \mathrm{~h}$. Raman spectroscopy was used to further examine the constituent phases. The Raman spectroscopy characteristic peak of $\theta$-alumina is about $220 \mathrm{~cm}^{-1}$, and the peak of $\alpha$-alumina is about $420 \mathrm{~cm}^{-1}[47,48]$. It is evident that the oxide that formed after 5 -h oxidation comprises both $\theta$-alumina and $\alpha$-alumina, while the oxide formed after 20 -h oxidation comprises only $\alpha$-alumina. So this additional experiment confirms the conclusion reached in section 4.1, i.e. the specimen without mechanical load initially produced $\theta$-alumina before the first 20 -h oxidation reaction, but with oxidation continuing, the $\theta$-alumina transferred into $\alpha$-alumina and eventually $\theta$-alumina disappeared after 20 -h oxidation.
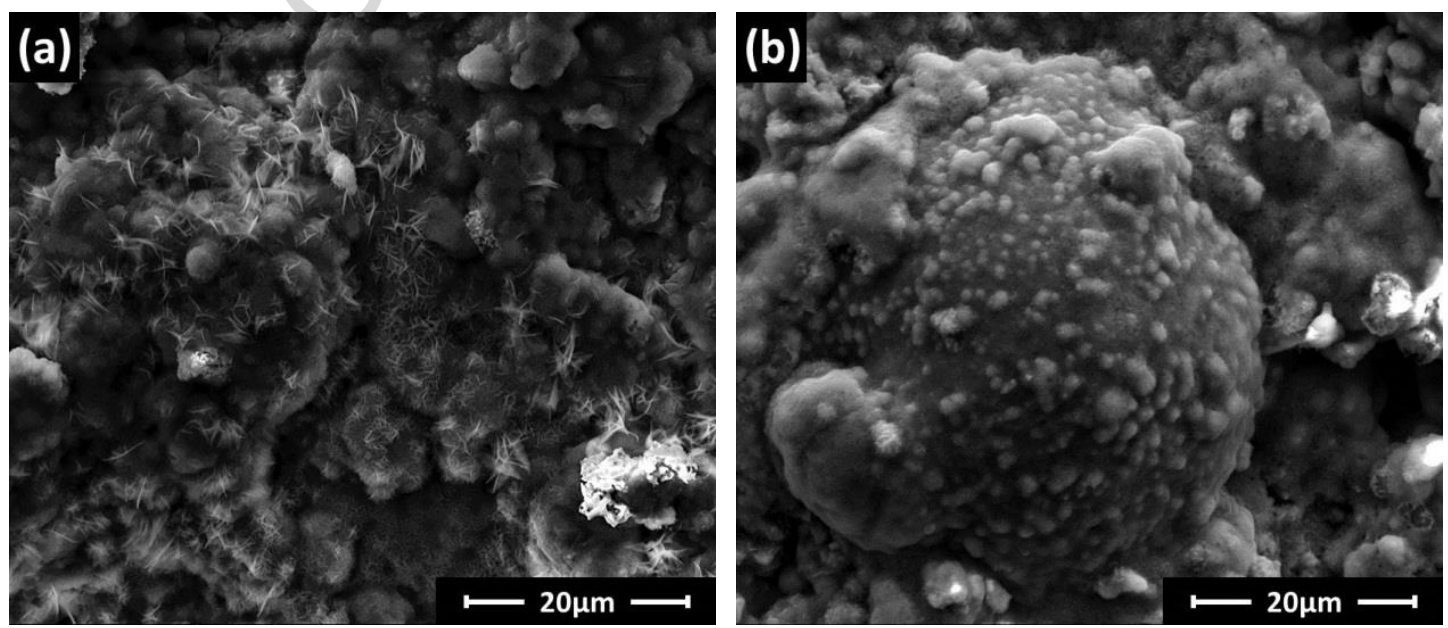
Fig. 8. Microscopic surface morphology of the additional coating specimen (disk wafer) without mechanical load after oxidation for $5 \mathrm{~h}$ (a) and $20 \mathrm{~h}$ (b).

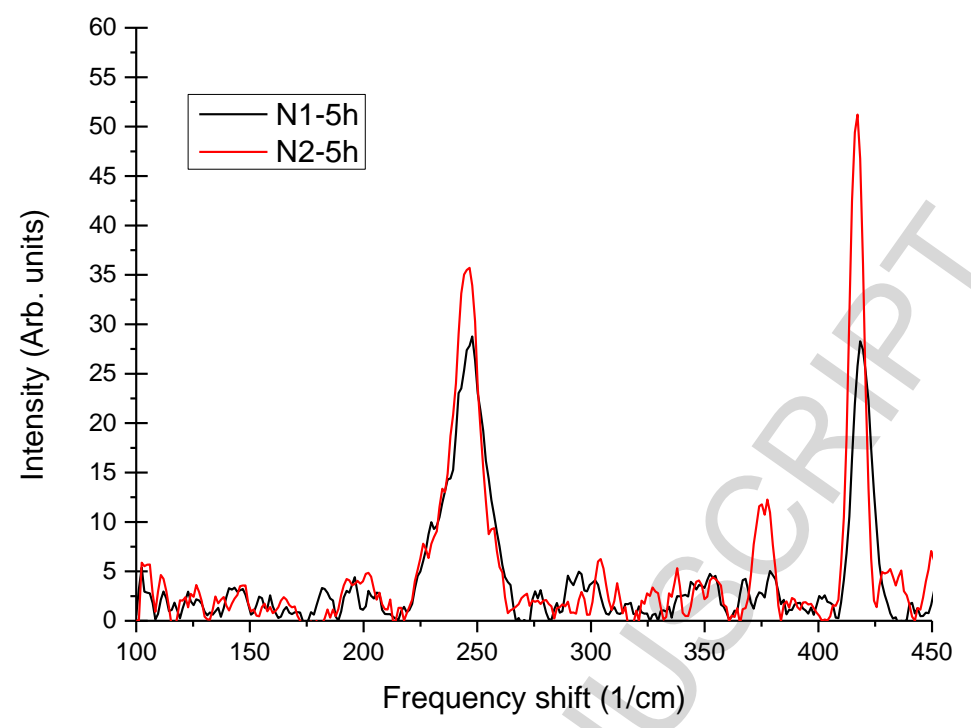

Fig. 9. Raman spectra obtained from two additional coating specimens (disk wafer) without mechanical load after oxidation for $5 \mathrm{~h}$.

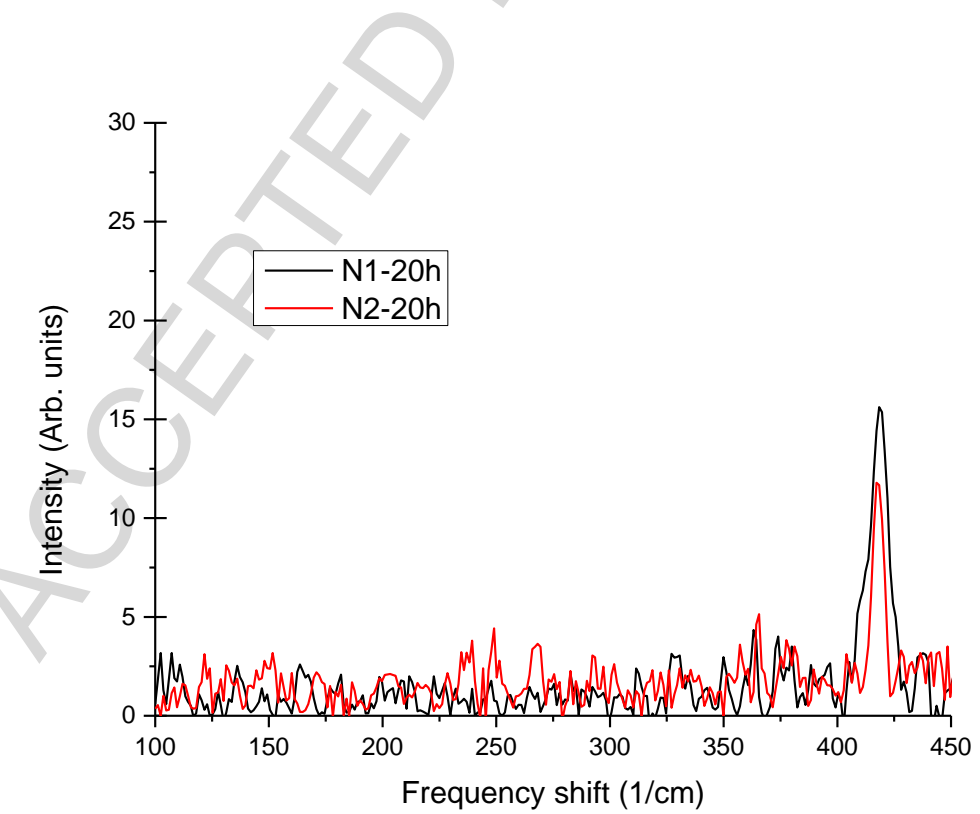

Fig. 10. Raman spectra obtained from two additional coating specimens (disk wafer) without mechanical load after oxidation for $20 \mathrm{~h}$. 


\section{Concluding remarks}

The chemo-mechanical coupling oxidation behavior of CoNiCrAlY coating is investigated by means of high temperature $\left(1000^{\circ} \mathrm{C}\right)$ experiment and theoretical model. The oxidation time ranged from $5 \mathrm{~h}$ to $60 \mathrm{~h}$ in experiments on both load-free and tension-loaded specimens. A chemo-mechanical coupling mechanism based on alumina phase transformation has been proposed to explain the experimental observation. The observations and conclusions are summarized as follows.

1. The oxidation rate of CoNiCrAlY coating was accelerated by tensile load (applied nominal tensile stress equal to $30 \mathrm{MPa}$ ).

2. The oxidation products were composed of both $\alpha$-alumina and $\theta$-alumina for high temperature oxidation time of $20 \mathrm{~h} / 40 \mathrm{~h} / 60 \mathrm{~h}$ under tensile load, and similar oxide microstructure was observed in the load-free specimen under short-duration oxidation $(\leq 15 \mathrm{~h})$. By contrast, only $\alpha$-alumina was formed in the load-free specimens after oxidation for $20 \mathrm{~h}$ or longer. This suggests that the tensile load can retard phase transformation from $\theta$-alumina to $\alpha$-alumina.

3. It has been theoretically demonstrated that the phase transformation from $\theta$-alumina to $\alpha$-alumina can be slowed down due to the effect of the mechanical work exerted by applied tensile load on the free energy, and consequently the tensile load can accelerate the oxide growth in the CoNiCrAlY coating since $\theta$-alumina has much higher growth rate than $\alpha$-alumina. 


\section{Acknowledgements}

This work was supported by National Nature Science Foundation of China (11472204, 1171101165). The authors appreciate the technical support from Mr. Dingjun Li for preparation of specimens. The first author is also grateful to Profs. Xiangdong Ding and Bingjun Ding for their comments and help.

\section{References}

1. Cao, X., et al., New double-ceramic-layer thermal barrier coatings based on zirconia-rare earth composite oxides. Journal of the European Ceramic Society, 2006. 26(3): p. 247-251.

2. Cao, X.Q., R. Vassen, and D. Stoever, Ceramic materials for thermal barrier coatings. Journal of the European Ceramic Society, 2004. 24(1): p. 1-10.

3. Evans, A.G., et al., Mechanisms controlling the durability of thermal barrier coatings. Progress in Materials Science, 2001. 46(5): p. 505-553.

4. Padture, N.P., Advanced structural ceramics in aerospace propulsion. Nature materials, 2016. 15(8): p. 804

5. Padture, N.P., M. Gell, and E.H. Jordan, Materials science - Thermal barrier coatings for gasturbine engine applications. Science, 2002. 296(5566): p. 280-284.

6. Evans, A., D. Clarke, and C. Levi, The influence of oxides on the performance of advanced gas turbines. Journal of the European Ceramic Society, 2008. 28(7): p. 1405-1419.

7. Evans, A.G., M.Y. He, and J.W. Hutchinson, Mechanics-based scaling laws for the durability of thermal barrier coatings. Progress in Materials Science, 2001. 46(3-4): p. 249-271.

8. Evans, A.G. and J.W. Hutchinson, The mechanics of coating delamination in thermal gradients. Surface \& Coatings Technology, 2007. 201(18): p. 7905-7916.

9. Meier Jackson, E., et al., Effect of surface preparation on the durability of NiCoCrAlY coatings for oxidation protection and bond coats for thermal barrier coatings. Materials and corrosion, 2008. 59(6): p. 494-500.

10. Kaplin, C., J. Fassoni, and M. Brochu, The Effect of Grain Size on the Cyclic Oxidation of NiCoCrAlY. JOM, 2014. 66(6): p. 1088-1095.

11. Karaoglanli, A., et al., A comparative study of the microabrasion wear behavior of CoNiCrAlY 
coatings fabricated by APS, HVOF, and CGDS techniques. Tribology Transactions, 2014. 57(1): p. 11-17.

12. Bai, Y., et al., Isothermal oxidation behavior of supersonic atmospheric plasma-sprayed thermal barrier coating system. Journal of thermal spray technology, 2013. 22(7): p. 1201-1209.

13. Pace, M. and R. Thomson, Oxidation of MCrAlY coatings on Ni based superalloys. Energy Materials, 2007. 2(3): p. 181-190.

14. Lau, H., et al., Influence of bondcoat pre-treatment and surface topology on the lifetime of EBPVD TBCs. Surface and Coatings Technology, 2003. 165(3): p. 217-223.

15. Karlsson, A.M., J. Hutchinson, and A. Evans, A fundamental model of cyclic instabilities in thermal barrier systems. Journal of the Mechanics and Physics of Solids, 2002. 50(8): p. 15651589.

16. Sun, Y., et al., Local stress around cap-like portions of anisotropically and nonuniformly grown oxide layer in thermal barrier coating system. Journal of Materials Science, 2013. 48(17): p. 5962-5982.

17. Sun, Y., et al., Local stress evolution in thermal barrier coating system during isothermal growth of irregular oxide layer. Surface and Coatings Technology, 2013. 216: p. 237-250.

18. Fan, X.L., et al., The effect of thermally grown oxide on multiple surface cracking in air plasma sprayed thermal barrier coating system. Surface \& Coatings Technology, 2012. 208: p. 7-13.

19. Yang, H., et al., Strong kinetics-stress coupling in lithiation of Si and Ge anodes. Extreme Mechanics Letters, 2015. 2: p. 1-6.

20. Hickenboth, C.R., et al., Biasing reaction pathways with mechanical force. Nature, 2007. 446(7134): p. 423.

21. Craig, S.L., Mechanochemistry: a tour of force. Nature, 2012. 487(7406): p. 176.

22. Evans, H., D. Norfolk, and T. Swan, Perturbation of parabolic kinetics resulting from the accumulation of stress in protective oxide layers. Journal of the Electrochemical Society, 1978. 125(7): p. 1180-1185

23. Zhou, H., J. Qu, and M. Cherkaoui, Stress-oxidation interaction in selective oxidation of $\mathrm{Cr}-$ Fe alloys. Mechanics of Materials, 2010. 42(1): p. 63-71.

24. Dong, X., et al., Diffusion and stress coupling effect during oxidation at high temperature. Journal of the American Ceramic Society, 2013. 96(1): p. 44-46.

25. Suo, Y. and S. Shen, General approach on chemistry and stress coupling effects during oxidation. Journal of Applied Physics, 2013. 114(16): p. 164905.

26. Loeffel, K. and L. Anand, A chemo-thermo-mechanically coupled theory for elastic-viscoplastic deformation, diffusion, and volumetric swelling due to a chemical reaction. International Journal of Plasticity, 2011. 27(9): p. 1409-1431.

27. Loeffel, K., L. Anand, and Z.M. Gasem, On modeling the oxidation of high-temperature alloys. Acta Materialia, 2013. 61(2): p. 399-424.

28. Takei, A. and K. Nii, Effects of Tensile Stress on High Temperature Oxidation of a Ni-2OCr4Al Alloy. Transactions of the Japan Institute of Metals, 1984. 25(8): p. 561-568.

29. Calvarin-Amiri, G., R. Molins, and A. Huntz, Effect of the application of a mechanical load on the oxide-layer microstructure and on the oxidation mechanism of $\mathrm{Ni}-20 \mathrm{Cr}$ foils. Oxidation of metals, 2000. 53(3-4): p. 399-426.

30. Zhou, C., H. Ma, and L. Wang, Effect of compressive stresses on oxidation kinetics and oxide 
scale failure of pure nickel at 973 K. Corrosion Engineering, Science and Technology, 2009. 44(5): p. 358-361.

31. Zhou, C., H. Ma, and L. Wang, A critical compressive stress for increasing the oxidation kinetics of Fe-20Cr alloy oxidized at 900 C. Oxidation of metals, 2009. 71(5-6): p. 335-341.

32. Zhou, C., H. Ma, and L. Wang, Comparative study of oxidation kinetics for pure nickel oxidized under tensile and compressive stress. Corrosion Science, 2010. 52(1): p. 210-215.

33. Fang, X., Mechanisms of Oxidative Ablation and Chemo-mechanical Coupling of High Temperature Structural Materials, Mechanics, (PhD Thesis), 2015, Tsinghua University.

34. Zhu, C., et al., The Effect of Initial Oxidation on Long-Term Oxidation of NiCoCrAlY Alloy. Engineering, 2010. 2(08): p. 602.

35. Ajdelsztajn, L., et al., Synthesis and oxidation behavior of nanocrystalline MCrAlY bond coatings. Journal of Thermal Spray Technology, 2005. 14(1): p. 23-30.

36. An, T., et al., Effect of the $\theta-\alpha-\mathrm{A} 12 \mathrm{O} 3$ transformation in scales on the oxidation behavior of a nickel-base superalloy with an aluminide diffusion coating. Oxidation of Metals, 2000. 54(3-4): p. 301-316.

37. Strauss, D., et al., Oxide scale growth on MCrAlY bond coatings after pulsed electron beam treatment and deposition of EBPVD-TBC. Surface and coatings Technology, 2001. 135(2-3): p. 196-201.

38. Dong, X., et al., Oxidation at high temperature under three-point bending considering stressdiffusion coupling effects. Oxidation of Metals, 2016. 86(1-2): p. 125-133.

39. Pint, B., J. Martin, and L. Hobbs, The oxidation mechanism of $\theta-\mathrm{A} 12 \mathrm{O} 3$ scales. Solid State Ionics, 1995. 78(1-2): p. 99-107.

40. Li, M., et al., Oxidation behavior of a single-crystal Ni-base superalloy in air. I: at 800 and 900 C. Oxidation of Metals, 2003. 59(5-6): p. 591-605.

41. Rybicki, G.C. and J.L. Smialek, Effect of the $\theta-\alpha-A 12$ O 3 transformation on the oxidation behavior of $\beta-\mathrm{NiAl}+\mathrm{Zr}$. Oxidation of Metals, 1989. 31(3-4): p. 275-304.

42. Gangwar, J., et al., Phase dependent thermal and spectroscopic responses of $\mathrm{Al} 2 \mathrm{O} 3$ nanostructures with different morphogenesis. Nanoscale, 2015. 7(32): p. 13313-13344.

43. Tamura, I., Deformation-induced martensitic transformation and transformation-induced plasticity in steels. Metal Science, 1982. 16(5): p. 245-253.

44. Patel, J. and M. Cohen, Criterion for the action of applied stress in the martensitic transformation. Acta Metallurgica, 1953. 1(5): p. 531-538.

45. Kao, H., W. Wei, and C.-Y. Huang, Two-stage densification of ultrafine transition alumina seeded with alpha-phase particulates. Journal of Ceramic Processing \& Research, 2003. 4(1): p. $34-41$.

46. Tolpygo, V. and D. Clarke, Microstructural study of the theta-alpha transformation in alumina scales formed on nickel-aluminides. Materials at High Temperatures, 2000. 17(1): p. 59-70.

47. Uran, S., et al., Optical investigation of the effects of substrate orientation on oxidation of single crystal $\beta$-NiAl. Oxidation of metals, 2001. 56(5-6): p. 551-569.

48. Renusch, D., et al., Pressure dependence of $\mathrm{Cr} 3+$ fluorescence in $\theta$-alumina. Oxidation of metals, 2001. 56(3-4): p. 299-311. 

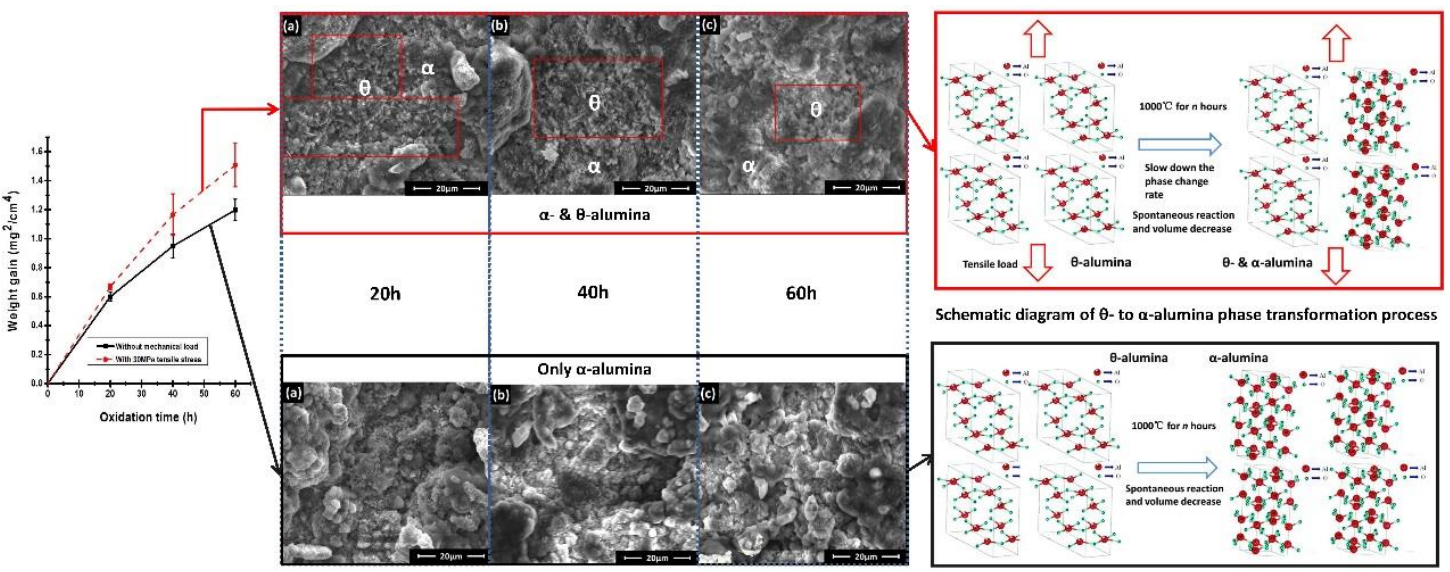

Schematic diagram of $\theta$ - to $\alpha$-alumina phase transformation process

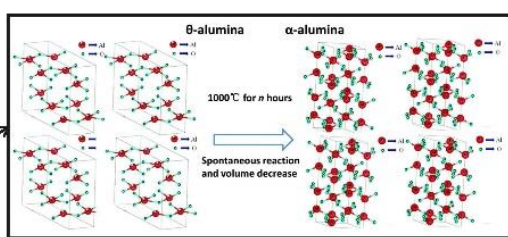

Graphical abstract 
Highlights

- Chemo-mechanical coupling oxidation behavior is investigated experimentally and theoretically

- New mechanism based on effect of mechanical work on phase transformation is proposed

- Tensile load accelerates oxidation of CoNiCrAlY coating at high temperature

- Transformation from fast-growing $\theta$-alumina to slow-growing $\alpha$-alumina is retarded by tensile load 